\title{
Biodegradable poly(lactic acid) microspheres containing total alkaloids of Caulis sinomenii
}

\author{
WEN ZHANG*, XIAOJIE LIN and XINGXIANG ZHANG \\ Institute of Functional Fibers, School of Materials Science and Engineering, Tianjin Polytechnic University, \\ Tianjin 300160, China
}

MS received 21 May 2010; revised 23 August 2010

\begin{abstract}
The fabrication of biodegradable poly(lactic acid) (PLA) microspheres containing total alkaloids of Caulis sinomenii was investigated. The formation, diameter, morphology and properties of the microspheres were characterized using Fourier transform infrared spectroscopy (FT-IR), laser particle size analyser and scanning electron microscopy (SEM), etc. In vitro releasing behaviour was also investigated using UV-Vis spectrometer. As a result, the drug-loaded microspheres with a narrower distributive, rounder and smoother surface were prepared. Drug-releasing behaviour from microspheres was affected by the concentration of emulsifier and the stirring rate. The results demonstrated that a medicated system, which can be potentially applied within a drug delivery system, was designed. This system acts in a systematic manner for the treatment of rheumatoid arthritis.
\end{abstract}

Keywords. Microsphere; Caulis sinomenii; PLA; drug release; rheumatoid arthritis.

\section{Introduction}

Rheumatoid arthritis (RA) is a chronic, systemic autoimmune inflammatory disease with prominent joint manifestations (Bresniham 1999; Gravallese 2002). Rheumatoid arthritis affects $0 \cdot 5-1 \%$ of the world's population and can occur at any age, especially at the age of 40-70 years, with a higher prevalence in females (Witten et al 2000; Firestein 2003). Diagnosis and long-term management are typically performed by a rheumatologist, an expert in the diseases of joints and connective tissues (Majithia et al 2007).

Caulis sinomenii, as the traditional Chinese medicinal herbal, can relieve symptom of rheumatosis, blood segregation and pain with low toxicity and side-effect based on the in-depth study of comprehensive experimental data in pharmacodynamics experiments (Tian et al 2000; Huang et al 2009). In connection with the aim of maximizing the bio-availability of conventional drugs with minimum side-effects, new drug delivery systems continue to attract much attention. One of them is the use of microcapsules/microspheres for delivering drugs to specific body sites.

Microencapsulation can protect core materials from, or release them into an outer phase for a long period. The major interest in the microencapsulation process is currently in the application of copying papers, cosmetics, adhesives, pharmaceutical and medical area (Hong and

\footnotetext{
*Author for correspondence (zhangwen2050@ hotmail.com)
}

Park 2000; Kim and Cho 2002; Giraud et al 2002, 2005; Chu et al 2004; Erkan and Sariisik 2004; Sawada and Urakawa 2005). Poly(lactic acid) (PLA) and its derivatives, with their outstanding biocompatibility and biodegradability, have become increasingly important in the development of biomedical fields (Shimori et al 2000; Rouzes et al 2003; Chognot et al 2003; Yin and Yates 2009). These polymers can either function as a matrix to control diffusion of the drug, followed by polymer biodegradation and elimination of the degradation products from the body, or participate in and control the rate of drug release by polymer hydration and degradation.

PLA and PLA/PEG microcapsules containing erythromycin were prepared with an emulsion solvent evaporation technique by Park and Kim (2004). It was found that the drug release rates of the microcapsules were significantly increased with the addition of PEG. In addition, Damge et al (1990) showed that nanocapsules were able to preserve and prolong the biological effect of insulin after oral administration. Nanoparticles were produced containing isradipine with the high entrapment efficiency of drug by Le-Verger et al (1998). Results from the investigation suggest that these nanoparticles can reduce the initial hypotensive peak and prolong the antihypertensive effect of the drug.

The objective of the present work was to prepare and characterize the microspheres containing total alkaloids from Caulis sinomenii with a view to develop medicated products that will enhance delivery systems relating to RA therapy and treatment. 


\section{Experimental}

\subsection{Materials}

PLA $\left(M_{\mathrm{w}}=40,000\right)$ obtained from Shenzhen Yixinsheng Material Co Ltd, China, was used as a wall-forming material. SMA (solid content is $19 \%$ of styrol maleic anhydride copolymer) as an emulsifying agent was purchased from Shanghai Leather Chemical Factory, China. Caulis sinomenii was purchased from Tianjin Dongbei Pharmacy (China). Sinomenine was purchased from Tianjin Yifang Technologices Co. Ltd. Dichloromethane and ethanol were obtained from Tianjin Chemical Reagent Factory as the analytical-reagent grade and used without any further purification. $\mathrm{NH}_{3}-\mathrm{H}_{2} \mathrm{O}, \mathrm{HCl}, 95 \% \mathrm{EtOH}, \mathrm{CHCl}_{3}$ and calcium oxide were purchased from Tianjin Chemical Reagent Factory.

\subsection{Preparation of total alkaloids from Caulis sinomenii}

The rhizomes of $C$. sinomenii were infiltrated with calcium oxide and water for $24 \mathrm{~h}$. The suspension was refluxed three times with $95 \% \mathrm{EtOH}$ for $4 \mathrm{~h}$ and concentrated to give a residue. The residue was soaked with $1 \% \mathrm{HCl}$ to elute the crude total alkaloids extracts. Then the extract was alkalized with $\mathrm{NH}_{3}-\mathrm{H}_{2} \mathrm{O}$ so that $\mathrm{pH}$ of the solution was 10.0. The solution was suspended in $\mathrm{CHCl}_{3}$ three times, and then filtered and concentrated to the pure total alkaloids. The productive rate of total alkaloids was about $1.2 \%$.

\subsection{Preparation of microspheres}

PLA microspheres were prepared by emulsion solvent evaporation method. PLA (1.5 g) was dissolved in dichloromethane $(30 \mathrm{ml})$, and then $0.15 \mathrm{~g}$ drug was added in polymer solution. $1.5 \%$ SMA water solution was used as the emulsifier. Polymer solution was mixed with SMA solution $(300 \mathrm{ml})$ and stirred at $2500 \mathrm{rpm}$ for $30 \mathrm{~min}$. Then the colloid solution was stirred continuously at $500 \mathrm{rpm}$ for $4 \mathrm{~h}$ until organic solvents were evaporated completely. The PLA microsphere suspension was rinsed three times with distilled water and prepared microspheres were collected by filtering and drying.

\subsection{Characterization}

2.4a Scanning electron microscopy analysis (SEM): The morphology and surface structure of microspheres were observed using a Quanta 200 (FEI) scanning electron microscopy.

2.4b Fourier transformed infrared spectroscopy (FT-IR) analysis: FT-IR spectra of the samples were measured using a Bruker TENSON37 Fourier transformed infrared spectroscopy (FT-IR) spectrophotometer in wavenumber range between 4000 and $400 \mathrm{~cm}^{-1}$ with a resolution of $4 \mathrm{~cm}^{-1}$.

2.4c Analysis of particle size distribution: Particle size distribution of the microspheres was determined using a LA-300 laser particle size analyser (HORIBA, Japan). This particle analyser can evaluate the particle sizes ranging from 0.5 to $2000 \mu \mathrm{m}$. The size distribution was estimated by fitting the intensity of the scattered light $(\lambda=750 \mathrm{~nm})$ as a function of the scattering angle. The particle diameter range, specific surface area, surface volume and mean diameter measurements were performed at room temperature.

\subsection{Drug content and in vitro drug release measurement}

Each batch sample of microshperes was dissolved in dichloromethane and the drug content was determined using SHIMADZU UV-2000-Vis spectra, at a wavelength of $265 \mathrm{~nm}$.

Drug microspheres, $100 \mathrm{mg}$, were suspended in $5 \mathrm{ml}$ ethanol at room temperature for about $10 \mathrm{~min}$ by ultrasound, and then the suspension was collected by filtering and drying. Then microspheres in the dialysis membrane containing $5 \mathrm{ml}$ water were incubated in a bath and then stirred at $100 \mathrm{rpm}$ in phosphate buffered saline (PBS, $200 \mathrm{ml}$ ) at $\mathrm{pH} \mathrm{7.4}$. The temperature was maintained throughout at $37 \pm 0 \cdot 5^{\circ} \mathrm{C}$. At specified time intervals, $5 \mathrm{ml}$ of samples were withdrawn, filtered through a micropore membrane and measured at $265 \mathrm{~nm}$. An equal volume of PBS was added to replace the sample that had been taken for UV measurement.

\section{Results and discussion}

\subsection{Morphologies}

The morphologies of the PLA microspheres fabricated at different concentrations of SMA are shown in figure 1 . Many micropores were observed on the surfaces of the microspheres fabricated at $1.0 \%$ SMA, compared with those fabricated at 1.5 and $2.0 \%$ SMA. The microspheres fabricated at $2.0 \%$ SMA had many fragments in the environment. This could result from the excessive amount of the emulsifier. Figure 2 showed the morphologies of the microspheres at different stirring rates. The mean diameter decreases with increasing the stirring rate. The microspheres had a uniform size distribution and smooth surfaces when the stirring rates were set at the rate of $2000 \mathrm{rpm}$ and $2500 \mathrm{rpm}$ (figures $2 \mathrm{a}$ and b). However, adhesion phenomena between microspheres were observed at the rate of $3500 \mathrm{rpm}$ (figure 2c). 


\section{$3.2 \quad F T-I R$ analysis}

FR-IR spectra of PLA (a), PLA microspheres containing total alkaloids extract from Caulis sinomenii (b) and total alkaloid extracts from Caulis sinomenii (c) were shown in figure 3. As shown in figures 3(a) and (b), adsorption peaks at 2960, 1759 and $1375 \mathrm{~cm}^{-1}$ were assigned to an aliphatic $\mathrm{C}-\mathrm{H}$ stretching vibration, $-\mathrm{C}=\mathrm{O}$ of ester and $\mathrm{C}-\mathrm{CH}_{3}$, respectively. The peak at $3425 \mathrm{~cm}^{-1}$ was in figures 3(b) and (c) assigned to the $\mathrm{O}-\mathrm{H}$, however, there was no peak in figure $3(\mathrm{a})$. The total alkaloid extracts
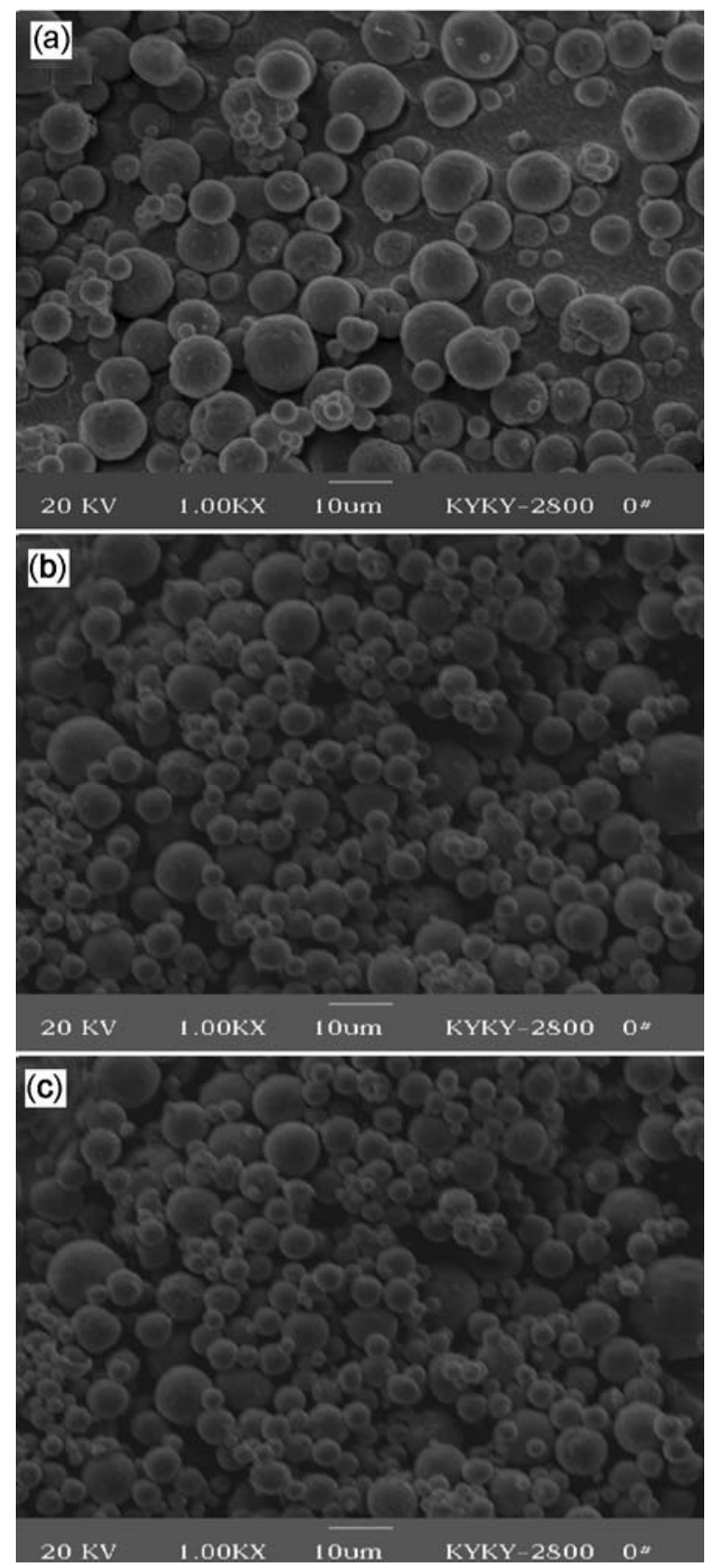

Figure 1. SEM photographs of drug microspheres fabricated at different concentrations of emulsifier: (a) $1.0 \%$ SMA; (b) $1.5 \%$ SMA and (c) $2.0 \%$ SMA. from Caulis sinomenii (c) showed characteristic peaks of alkaloid (e.g. the stretching vibration of methylene $\left(-\mathrm{CH}_{2}-\mathrm{N}\right)$ and the stretching vibration of ester $(-\mathrm{C}=\mathrm{O})$ at 2850 and $1690 \mathrm{~cm}^{-1}$, respectively). The existence of total alkaloid extracts on the PLA microspheres is confirmed by FT-IR.

\subsection{Particle size distribution}

Figure 4 presented the particle size distribution of the microspheres with different stirring rates. Mean sizes of
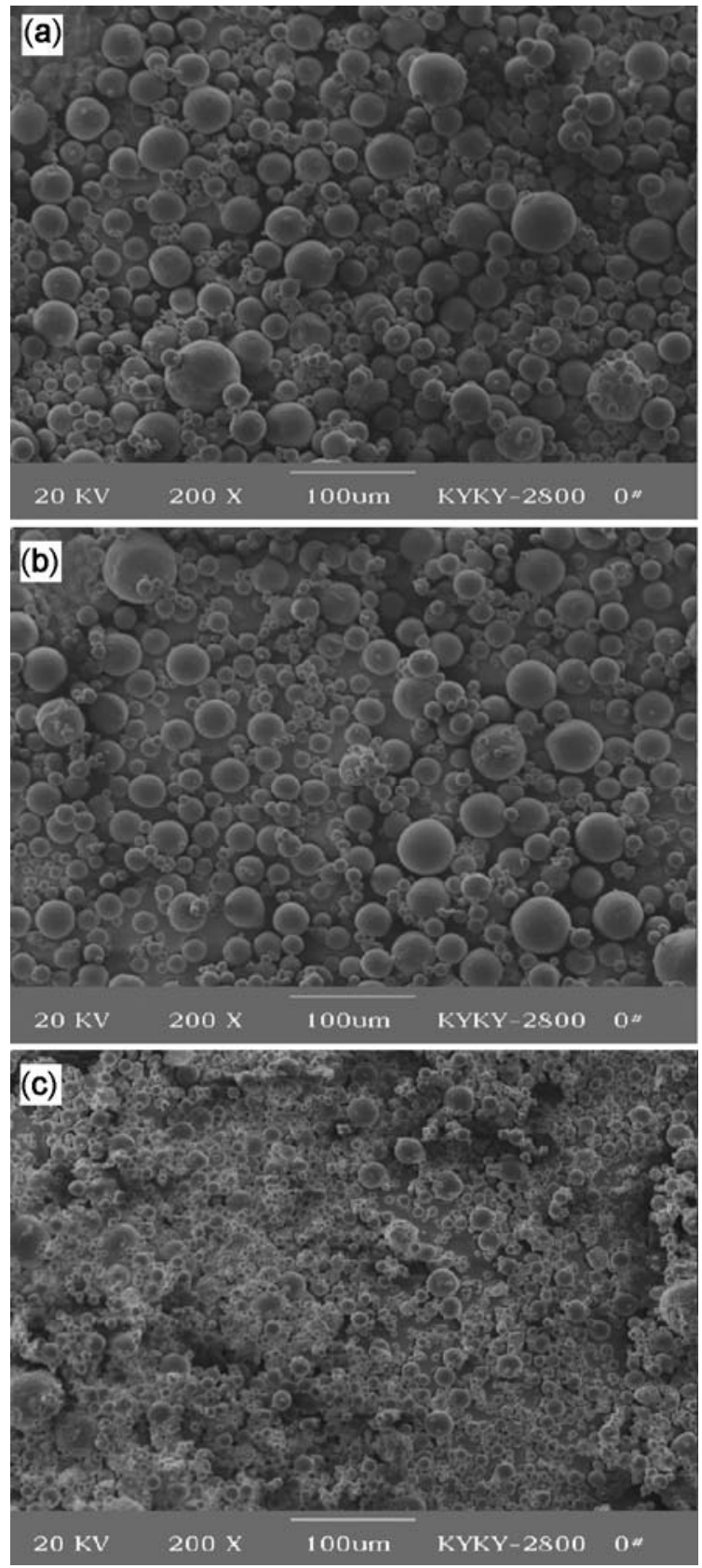

Figure 2. SEM photographs of drug microspheres fabricated at different stirring rates: (a) $2000 \mathrm{rpm}$; (b) $2500 \mathrm{rpm}$ and (c) $3500 \mathrm{rpm}$. 
the microspheres for figures $4 \mathrm{a}, \mathrm{b}$ and $\mathrm{c}$ were $8 \cdot 37,21 \cdot 54$ and $35 \cdot 16 \mu \mathrm{m}$, respectively. The width of the distribution curves was similar in figures $4 \mathrm{a}, \mathrm{b}$ and $\mathrm{c}$. Thus, the microspheres under the condition appeared to have a narrow size distribution. In addition, it found that the particle size increases with slower stirring rates in the test.

\subsection{In vitro releasing behaviours of microspheres}

The in vitro release of drug microspheres in $\mathrm{pH} 7.4 \mathrm{PBS}$ at $37^{\circ} \mathrm{C}$ was presented in figure 5. All samples demonstrated an initial burst of drug release, about $20-40 \%$ of the total within the first $2 \mathrm{~h}$ of incubating. Thereafter

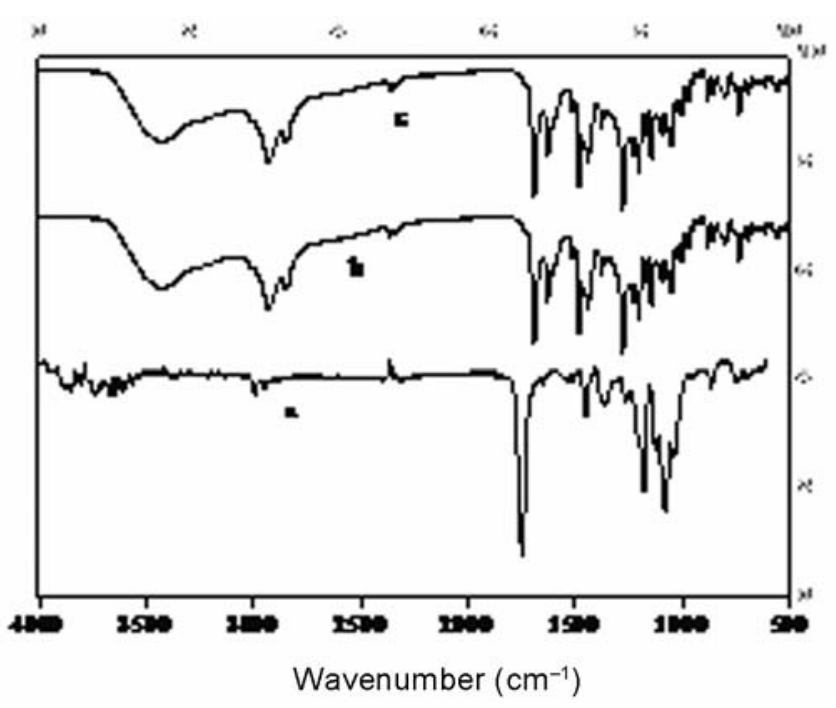

Figure 3. FT-IR spectra of (a) PLA; (b) PLA microspheres containing total alkaloids extracts from Caulis sinomenii and (c) total alkaloids extracts from Caulis sinomenii.

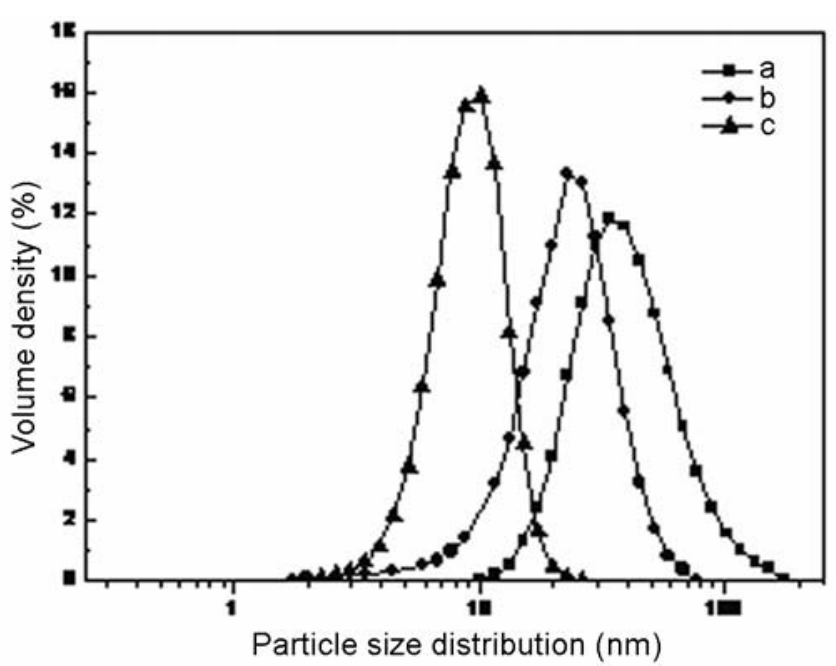

Figure 4. Particle size distribution of drug microspheres: (a) $3500 \mathrm{rpm}$; (b) $2500 \mathrm{rpm}$ and (c) $2000 \mathrm{rpm}$. there was a steady release of material into the medium. The reason may be that a significant loading of drug was located in the vicinity of the microsphere surface and this was released as the sphere swells and the cavity size increases.

In this study, the release rate from the microspheres fabricated at $1.5 \mathrm{wt} \%$ SMA (figure $5 \mathrm{~b}$ ) was slower than those from the microspheres fabricated at 1 and $2 \mathrm{wt} \%$ SMA (figures 5a and c). This presents the effect of wall roughness, and so the release rate of a penetrator from the wall became slower with the increase on the surface roughness. The mean diameter of microspheres significantly affected the release rate. Drug for the larger microspheres will take more time to gradually move from the inside of microspheres to the surface at the time of incubation proceeds (figures $5 \mathrm{~b}, \mathrm{~d}$ and e). On the other hand, the rate-limiting step in drug release was the rate of polymer swelling or drug diffusion within the polymer matrix (Messaritaki et al 2005). So, with an increasing drug/polymer ratio of $1 / 5-1 / 10(\mathrm{~g} / \mathrm{g})$ and $1 / 15(\mathrm{~g} / \mathrm{g})$ (figure $5 \mathrm{~b}, \mathrm{f}$ and $\mathrm{g}$ ), the release of drug in the first $2 \mathrm{~h}$ from the microspheres was $19.4 \%, 23.6 \%$ and $52.4 \%$, respectively.

\section{Conclusions}

PLA microspheres containing total alkaloids of Caulis sinomenii were prepared by the emulsion solvent evaporation method. PLA microspheres were seen to be spherical and smooth in structure with a mean diameter in the range of $8-35 \mu \mathrm{m}$. An initial high burst, effect was observed for all preparations during the in vitro release studies within the first $2 \mathrm{~h}$ of incubating, which was due to the drug adsorbed on the surface of the microspheres.

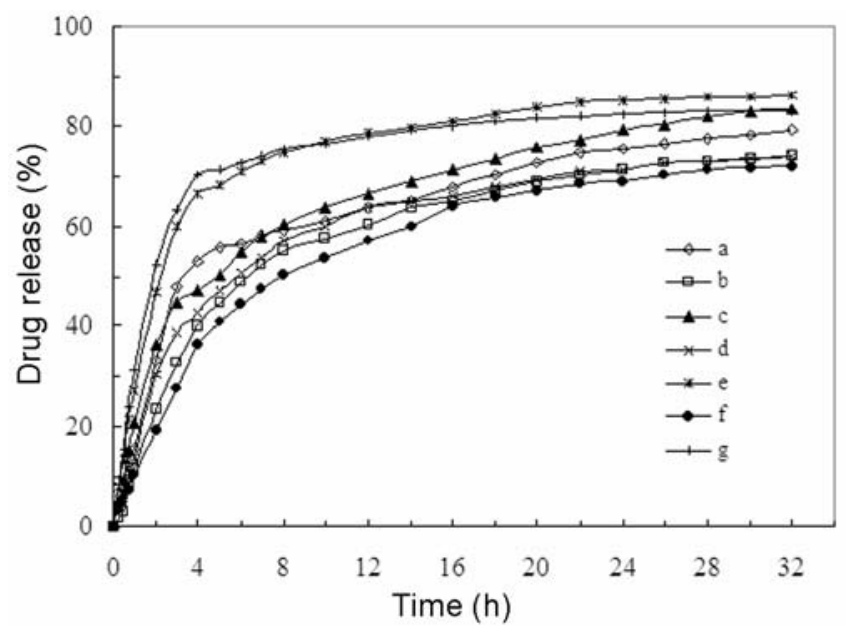

Figure 5. Cumulative release rate of microspheres prepared at different conditions in $\mathrm{pH} 7.4$ PBS. (a) $1.0 \mathrm{wt} \%$ SMA; (b) $1.5 \mathrm{wt} \%$ SMA; (c) $2.0 \mathrm{wt} \% \mathrm{SMA}$; (d) stirring at $2000 \mathrm{rpm}$; (e) stirring at $3500 \mathrm{rpm}$; (f) drug/polymer ratio: $1 / 5(\mathrm{~g} / \mathrm{g})$ and (g) drug/polymer ratio: $1 / 15(\mathrm{~g} / \mathrm{g})$. 
Then steady states were reached as time of incubation increased.

A process that produces the PLA microspheres containing the traditional Chinese medicine was developed. An anti-RA drug can be encapsulated in a form where it is stable and the compounds can be released over a period of time. All formulations are good candidates for our future studies of delivery system relating to the therapy and treatment of RA.

\section{Acknowledgements}

We are grateful to Instrumental Analysis Center of Materials Science and Engineering, Tianjin Polytechnic University for the help in characterization.

\section{References}

Bresniham B 1999 J. Rheumatol. 26717

Chognot D, Six J L, Leonard M, Bonneaux F, Vigneron C and Dekkacherie E 2009 Colloid Interf. Sci. 268441

Chu L Y, Liang Y J, Chen W M, Ju X J and Wang H D 2004 Colloids Surf. B: Biointerf. 379

Damge C, Miche L C, Aprahamian M, Couvreur J P and Devissaguet J P 1990 J. Control. Release 13233
Erkan G and Sariisik M 2004 Colourage Annual. 61

Firestein GS 2003 Nature $\mathbf{4 2 3} 356$

Giraud S, Bourbigot S, Rochery M, Vroman I, Tighzert L and Delobel R 2002 Polym. Degrad. Stabil. 77285

Giraud S, Bourbigot S, Rochery M, Vroman I, Tighzert L, Delobel R and Poutch F 2005 Polym. Degrad. Stabil. 88106 Gravallese E M 2002 Ann. Rheum. Dis. 61 ii84

Hong K J and Park S M 2000 Polymer 414567

Huang Z Y, Zhang Y H, Zhou L, Li Z and Yang X S 2009 Chinese Traditional \& Herbal Drugs 40193

Kim J and Cho G 2002 Textile Res. J. 721093

Le-Verger M L, Fluckiger L, Kim Y I, Hoffman M and Maincent P 1998 Eur. J. Pharm. \& Biopharma. 46137

Majithia V and Geraci S A 2007 Am. J. Med. 120936

Messaritaki A, Black S J, van der Walle C F and Rigby S P 2005 J. Control. Release 108271

Park S J and Kim S H 2004 J. Colloid \& Interf. Sci. 271336

Rouzes C, Leonard M, Durand A and Dellacherie E 2003 Colloids Surf. B: Biointerf. 32125

Sawada K and Urakawa H 2005 Dyes Pigments 6545

Shimori K, Kawano Y and Kiyoyama S 2000 Kagaku Kogaku Ronbunshu. 250

Tian G Z and Pang B S 2000 Xi'an United University (Natural Sciences Edition) 326

Witten T M, Del Rincon I and Escalante A 2000 Math. \& Computer Modelling 3131

Yin W S and Yates M Z 2009 J. Colloid \& Interf. Sci. 336155 